\title{
BILBAO, UNA DIÓCESIS DE CINCUENTA AÑOS
}

POR

\section{ANABELLA BARROSO ARAHUETES}

\section{RESUMEN}

La diócesis de Bilbao es de las últimas que se funda en la España eclesiástica, por lo que el presente estudio es un recorrido sistemático por toda su existencia. En él se marcan las diferentes vicisitudes que atraviesa, incidiendo en los problemas de la falta de clero en las últimas décadas

\begin{abstract}
The diocese of Bilbao is almost the last one founded in Spain. The present study is a systematical tour all over its existence and shows the different ways that crosses, especially the problem of no vocations in the last decades.
\end{abstract}

La diócesis de Bilbao abarca el Territorio Histórico de Bizkaia a excepción del enclave de Orduña que pertenece a la diócesis de Vitoria y el municipio de Villaverde de Trucios que, aunque encuadrado en Cantabria, está integrado en la diócesis bilbaina. No hay datos que permitan fijar con exactitud la época de la evangelización de Bizkaia. Ciertos indicios arqueológicos permiten suponer que tal vez se iniciara en en el Bajo Imperio Romano. Los primeros datos documentales no aparecen hasta el siglo XI y nos presentan iglesias esparcidas por todo el territorio vizcaino.

En un principio, toda Bizkaia, menos su parte autrigona, debió pertenecer a la sede de Pamplona, de la que se desprendió para pasar a la diócesis de Alava,

Actas del I Congreso de Historia de la lglesia y el Mundo Hispánico

Hispania Sacra, 52 (2000) 
con sede en Armentia, cundo ésta se creó en un momento no conocido con exactitud del siglo XI. Hacia 1088 la diócesis de Alava es absorbida por Calahorra, de la que depende hasta 1861, año en que se erigió la diócesis de Vitoria que, de acuerdo con el Concordato de 1851, reunió a las entonces llamadas Provincias Vascongadas. La zona de las Encartaciones dependió primero de Oca y luego de Valpuesta, hasta que esta fue absorbida por Burgos. En 1754 parte de las parroquias vizcaínas dependientes de Burgos, pasaron a Santander y en 1861 todas pasaron a la jurisdicción de la nueva sede vitoriana.

La bula Quo Commodius del 2 de noviembre de 1949 dispuso la erección de la diócesis de Bilbao. Fue ejecutada por el nuncio apostólico, Monseñor Cicognani. Desde su creación, la diócesis ha estado inmersa en situaciones sociopolíticas y culturales de cierta tensión heredadas de la guerra civil. La especial configuración del régimen político español, nacido de aquella guerra, dio lugar a una difícil convivencia civil y religiosa.

\section{LA CALMA TENSA DE LA POSGUERRA: UNA IGLESIA DE VENCEDORES Y VENCIDOS}

La guerra civil truncó, entre otras muchas cosas, la floreciente Iglesia del País Vasco y contribuyó a ahondar las disensiones internas, afiadiéndose desde entonces la distinción entre una Iglesia vencedora y una Iglesia vencida. La actuación de parte de la clerecía del País Vasco, desde entonces conocido como "clero vasco», ponía en evidencia la falsedad de la propaganda franquista e invalidaba, en parte, una de las más valiosas fuentes de legitimación del levantamiento del 18 de julio y del régimen surgido tras la victoria del bando sublevado.

Con esta profunda herida de guerra, cicatrizada en falso, iniciaba la Iglesia en el Pais Vasco un nuevo e intrincado camino. El Obispo de Vitoria, Monseñor Laucirica, optó por la vía de la espiritualidad que se presentaba equidistante de las partes enfrentadas sin apoyar públicamente a ninguna de ellas. Potenció la línea pastoral y religiosa anterior a la guerra civil, promoviendo un estilo de sacerdote con profunda espiritualidad y trató, por encima de todo, de evitar todo compromiso temporal, sobrevalorando el lema de don Rufino Aldabalde, «sólo sacerdote, siempre sacerdote y en todo sacerdote». El llamado movimiento sacerdotal de Vitoria sirvió para prolongar un estilo pastoral de cercanía a las personas, algo que había distinguido a la clerecía vasca.

La espiritualidad del movimiento sacerdotal de Vitoria contrastaba con los excesos cometidos en esos años por el nacionalcatolicismo y consolidó el florecimiento de los estudios del Seminario. Podemos decir que en estos años, en el País Vasco, se acentúa la dicotomía entre iglesia popular e iglesia oficial. La 
jerarquía eclesiástica aliada con la oligarquía vasca, de tendencia españolista y con poder real, deja de lado al mundo obrero y a amplios sectores nacionalistas que contaban con el apoyo del clero y viceversa. Mientras un sector del clero y una parte de la feligresía se sentían atraídos por las diversas formas del tradicionalismo, el Obispo de Vitoria se sentaba junto a otros prelados españoles en las primeras cortes franquistas.

Pero no todo era colaboración con el régimen. Una extensa carta dirigida por curas vascos al Vaticano el 25 de noviembre de 1944 fue el primer eslabón de una larga cadena de protestas clericales que desde el País Vasco elevaron su voz, mediante una carta-denuncia, para condenar los atropellos del régimen y defender los derechos humanos más allá de los límites de su diócesis, en medio del silencio de otras fuerzas políticas y sociales. Esta carta al Vaticano no tuvo mayor trascendencia a corto plazo, pero la protesta del clero vasco era la mejor y más peligrosa propaganda anti-régimen en una sociedad tan profundamente religiosa como la vasca en la que sus sacerdotes gozaban de un gran ascendiente. El régimen quiso ver confirmadas las sospechas de separatismo sobre un sector del clero de las diócesis vascas y con esa suspicacia, convertida en obsesión, emprendió una política para intentar domeñar o al menos asegurarse el apoyo de la mayoría de una Iglesia vasca conflictiva.

En noviembre de 1949 una bula pontificia desgajaba de la macrodiócesis vitoriana los territorios de las provincias de Bizkaia y Gipuzkoa. Cada una recibió el nombre de las capitales vizcaína y guipuzcoana, respectivamente, quedando constituidas la de San Sebastián por la provincia de Gipuzkoa y la de Bilbao por la provincia de Bizkaia, a excepción de Orduña que continuaba permaneciendo dentro del obispado vitoriano. La desmembración de la diócesis respondía a razones pastorales. Pero, no cabe ninguna duda de que fueron motivos políticos los que lograron que Roma accediera a tal reajuste. Además, el nombramiento de obispos no vascos para las nuevas sedes no pasó desapercibido para un sector del clero vasco que empezó a protestar por el silencio jerárquico ante la represión o el uso de símbolos franquistas en los templos.

Desde entonces estas serán las principales reivindicaciones de un sector del clero en las diócesis vascas. Pronto, surgió la iniciativa de publicar unas hojas clandestinas para informar sobre la situación y los problemas pastorales y sociopolíticos de las diócesis vascas. Así, en marzo de 1950 aparece la revista Egiz que, en sus 18 números, criticó las arbitrariedades del régimen, reivindicó los derechos del pueblo vasco y planteó en toda su gravedad el problema de la autonomía y libertad de la Iglesia.

Más importante que la división de la sede vitoriana fue el hecho de que en 1956 Pamplona se convirtiera en arzobispado, siendo la diócesis de San Sebastián una de sus sufragáneas, mientras Bilbao y Vitoria continuaron en la archi- 
diócesis de Burgos. Desde entonces, la remodelación de la provincia eclesiástica de Pamplona será una de las principales reivindicaciones de parte del clero vasco.

\section{LA DÉCADA DE LOS 50: EL RODAJE DE LAS NUEVAS DIOCESIS}

Una vez desmembrada la diócesis de Vitoria, las tres demarcaciones eclesiásticas que de ella surgieron tuvieron que preocuparse individualmente por hacerse con los efectivos clericales necesarios para atender a sus respectivas feligresías. Los nuevos obispos se esforzaron por potenciar e institucionalizar la herencia recibida de la diócesis vitoriana. La formación de los cabildos necesarios, nombramientos, organización de la actividad pastoral, creación de parroquias... ocuparon los primeros cinco aftos de mandato de los nuevos obispos, cuyo primordial objetivo fue dar una sólida infraestructura organizativa y pastoral a las nuevas sedes.

La creación de las nuevas diócesis tuvo lugar en un momento de cambio y transformaciones socioeconómicas en las tres provincias vascas, pero sobre todo en Bizkaia y Gipuzkoa. Junto a las necesidades más perentorias de equipamiento de muchos barrios nuevos, los sacerdotes se enfrentaron al reto de acercar la Iglesia a unas masas obreras cada vez más alejadas. Durante estos años, el Obispo que llega a Bilbao, don Casimiro Morcillo, lleva a cabo la puesta en marcha del entramado diocesano. La creación de nuevas parroquias ocupa buena parte de las actividades del nuevo Obispo que, en 1956, será sustituido por don Pablo Gúrpide. Mientras la Iglesia vasca se adaptaba a su nueva situación, Franco firmaba, en 1953, un Concordato con la Santa Sede que sellaba el momento de mayor predominio de la Iglesia dentro del Régimen.

La pastoral entonces vigente intenta el encuadramiento de los fieles en organizaciones masivas dirigidas por la Iglesia. Pero poco a poco, parte del clero optó por una predicación testimonial destacando la dignidad y los derechos inalienables de la persona y del trabajador así como los deberes de los empresarios de respetar las libertades de sus obreros. Los ejercicios espirituales en fábricas de finales de los af́os 40 y de la década de los 50 tuvieron un gran éxito. De estos ejercicios salieron muchos futuros militantes de movimientos especializados de la Acción Católica. En torno a dichos movimientos que atienden a las siglas HOAC, VOJ, JOC Y JARC, los curas vascos cristalizaron el descontento cristiano ante una Iglesia a la que se quería más pobre y comprometida. La labor de concienciación obrera de estos grupos fue fundamental, dando coherencia a las huelgas espontáneas que fueron sucediéndose en los primeros años de la década. Y, ya desde entonces, se observó en el clero vasco una toma de postura 
a favor de los obreros, proclamando la licitud de la huelga para reivindicar unas aspiraciones legítimas.

En estos años de fuerte compromiso temporal entre la legalidad y la temporalidad, la HOAC vive, de hecho, fuertes tentaciones de «temporalismo, dualismo y suplenciay. No faltaron desde entonces las suspicacias civiles contra estos movimientos que, amparados en la Iglesia, escapaban al control del régimen franquista. La desconfianza fue manifiesta cuando en 1953, después de la Semana Social, los obreros de Euskalduna salieron a la huelga. La suerte estaba echada. Lo social se convirtió en la estrella de la acción pastoral cotidiana en el País Vasco. Un plantel de sacerdotes bien formados en cuestiones sociales en el Seminario de Vitoria fue el encargado de, con diferentes matices, acercarse al mundo obrero.

Con el aumento de tensiones en 1956, Bizkaia y Gipuzkoa vieron agitarse una vez más su vida cotidiana con las huelgas y muchos sacerdotes fueron sancionados o amonestados por las autoridades eclesiásticas y/o civiles que les relacionaron con las huelgas. Las activas promociones de curas de finales de la década de los 50 se convierten en las proveedoras de sacerdotes a las filas del clero vasco. Durante estos años, al hilo de los acontecimientos económicos y las huelgas y protestas sociales, el clero vasco va elevando sus quejas mediante cartas colectivas. Veinte años después de la guerra civil las demandas a favor del pueblo vasco continuaban siendo las mismas, pero las nuevas generaciones sacerdotales consideraban que había que hacer algo más que promocionar el renacimiento cultural vasco y el cultivo del euskera. Algunos curas decidieron renovar las tácticas y dar prioridad en las demandas del clero vasco a la liberalización del pueblo vasco. Empezaron, entonces, a preparar un documento reivindicativo de los derechos de su pueblo.

Pocos meses después, la calma tensa de las diócesis vascas estalla cuando 339 sacerdotes vascos dan a conocer un escrito con el que las reivindicaciones nacionalistas del pueblo vasco entran en escena. Comienza así una etapa enormemente conflictiva para las diócesis vascas, en la que el clero vasco, a remolque de las circunstancias, irán renovando sus tácticas reivindicativas. Las demandas nacionalistas desbancan a las sociales. Ceden terreno y protagonismo ante el empuje, la decisión del clero y la contundente reacción de las autoridades civiles y eclesiásticas, mucho más preocupadas por las intromisiones de los sacerdotes en las cuestiones temporales. Las comunidades diocesanas sufrirán la división al no estar de acuerdo todos sus miembros con las peticiones y los procedimientos de sus compañeros de sacerdocio. Si durante la década de los 50 la iniciativa de la protesta clerical surgía en Gipuzkoa, en las décadas siguientes la actuación episcopal en la diócesis bilbaina exacerbará tanto las posturas que marcará la pauta en la protesta sacerdotal, alcanzando unas altas cotas de conflictividad. 


\section{LA DÉCADA DE LOS 60: EL INICIO DE LA RADICALIZACIÓN}

El documento de los 339 inaugura una nueva etapa en la actuación del clero vasco. Al analizar y denunciar la situación sociopolítica, acusa al régimen y a la jerarquía de la falta de libertades que, desde la guerra civil, sufren España en general y el País Vasco en particular. No es la primera vez que un sector del clero vasco critica al régimen politico instaurado en España tras la guerra civil. Pero en esta ocasión realizan un ataque frontal al sistema franquista. Al presentar como una descarada contradicción con la doctrina católica unas determinadas pautas de comportamiento, inculpan al régimen responsable de esas conductas, cuestionando abiertamente su legitimidad. Y decir que un régimen es ilegitimo es dar razones y un espaldarazo moral a todos los movimientos de oposición al mismo. Además, están legitimando la oposición al franquismo en aras de una liberación del pueblo vasco. El malestar que existía en una parte de la población del País Vasco desde la guerra civil ha salido a la palestra de la mano de este grupo de sacerdotes, que se hace eco de las reivindicaciones nacionalistas.

Con este documento ponen fin a la etapa en que sólo se movían en el terreno de las ideas en cuestiones políticas. Sin abandonar la clandestinidad pasan al terreno de la acción. Así, inician una nueva etapa. Con esta carta optan por la denuncia colectiva. Su ejemplo no tardará en ser seguido, inaugurando una línea de denuncia profética. A partir de entonces, muchos sacerdotes (algunos firmantes entre ellos) incluyeron entre sus obligaciones la de denunciar las injusticias y la de censurar desde los púlpitos muchos de los desmanes del régimen. Prestan una especial atención a las reivindicaciones nacionalistas que protagonizarán todos los conflictos del clero vasco con las autoridades civiles y eclesiásticas.

La gran divulgación alcanzada por el documento desata una abierta desconfianza hacia el clero firmante y explica la contundente, aunque cautelosa y prudente, actuación de las autoridades civiles y eclesiásticas que ejercieron represalias contra los firmantes. Las diversas posturas ante el documento y sus críticas nos permite detectar la existencia de tres grupos dentro de cada diócesis. Un sector es el que podemos denominar contestario caracterizado en este caso por apoyar $\mathrm{y} / \mathrm{o}$ haber firmado el documento. Por otro lado se halla el sector oficial que, mostrando una postura contraria a la del anterior, va a defender siempre y en todo momento la figura del Obispo. A caballo entre los dos anteríores, un tercer grupo más numeroso en las tres diócesis intenta comprender a los Obispos y, a la vez, a los sacerdotes firmantes. Su trascendencia radica en que un acontecimiento concreto fue el detonante que puso al descubierto una situación general: la división que en esas fechas recorría las diócesis vascas,

Actas del 1 Congreso de Historia de la Iglesia y el Mundo Hispánico

Hispania Sacra, 52 (2000) 
sobre todo las sedes bilbaina y donostiarra. División que, por otra parte, no hará sino aumentar considerablemente a lo largo de los años posteriores.

Cuando aun no estén ahogados los ecos del documento de los 339 , otras actuaciones sacerdotales, entre ellas un documento al Concilio, irrumpirán en la intrincada escena de las diócesis vascas, sobre todo guipuzcoana y vizcaina, provocando una serie de conflictos internos y externos. El clero vasco toma la iniciativa en dos direcciones paralelas: el problema obrero y el problema nacional. Desde el púlpito, llaman la atención sobre las situaciones reales de marginación y pobreza de la población obrera, en su mayor parte inmigrante, y denuncian las torturas, remarcando el valor de los derechos naturales de la persona humana y de los pueblos como superior a la legalidad vigente.

Las autoridades civiles no aceptarán nunca de buen grado la intromisión de sacerdotes en los asuntos temporales y presionan a la jerarquía eclesiástica para que ataje la indisciplinada actitud de sus subordinados. Pero, a su vez, el régimen intentará desde muy pronto atajar este tipo de sermones, pero choca con el Concordato y con la imposibilidad de juzgar a los sacerdotes en el ejercicio de la predicación. A medida que avance la década de los 60 , el régimen no buscará ningún tipo de excusa y muchas predicaciones engrosarán la lista de homilías multadas a la vez que las autoridades civiles aplicarán sanciones a los sacerdotes que lleven a cabo acciones contrarias al régimen.

El propio clero decide, a partir de 1965, utilizar medios de protesta más contundentes tales como las concentraciones de sacerdotes ante el juzgado de Bilbao. Sin dejar de utilizar el púlpito como medio de oposición al régimen, desde 1964 un grupo de sacerdotes alentó, cuando no participó, en las manifestaciones del $1^{\circ}$ de mayo y en las del Aberri Eguna. En esos afíos las posturas, las exigencias y las actuaciones de este sector del clero evolucionan hacia la radicalización. Ese proceso está jalonado por numerosas homilías e intervenciones comprometidas en asuntos temporales.

Todo este proceso coincide con los años en que la Iglesia española no puede aplazar la reforma litúrgica y la acomodación, al menos formal, a las nuevas directrices dictadas por el Vaticano II. Su reconocimiento de los valores de la libre autodeterminación, de los derechos humanos y de la solidaridad ofrecía en la situación social y política vigente en los años de recepción conciliar un material candente. El gobierno de las diócesis, especialmente de Bilbao, se convierte en una engorrosa tarea. No cuentan con la adhesión de todos los sacerdotes. Les falta, sobre todo, el apoyo del grupo que, sin excluir la posible desobediencia a sus superiores, había optado por la acción directa como fórmula más eficaz. $\mathrm{Ni}$ sus reivindicaciones sociopolíticas ni las pastorales hallan respuesta alguna en la jerarquía. Las autoridades eclesiásticas de las diócesis vascas no comprendieron y desatendieron las demandas de ese sector del clero. En el marco más 
amplio de las relaciones Iglesia-Estado, no supieron o no pudieron colmar sus peticiones. Tiene lugar, entonces, el progresivo distanciamiento de ese grupo de sacerdotes, auténtica pesadilla de autoridades civiles y eclesiásticas.

La HOAC y la JOC se fueron prestigiando en el mundo obrero por su participación e implicación en la problemática sindical. Sacerdotes y consiliarios forjaron el espíritu de los militantes obreros para intervenciones encaminadas a la acción y al compromiso. El paso del «hay que» al «estamos luchando por» dado por estos movimientos en la década de los 60 les permitió cosechar sus mayores cotas de éxito entre los obreros. Pero, su eficacia incubaba el germen de su decadencia. No todos los militantes se conformaron con pequeñas actividades semanales. Ampliaron su campo de acción. Unos se dedicaron al sindicalismo, algunos al cooperativismo, otros a la lucha clandestina por la justicia. Unas organizaciones obreras de la Iglesia pujantes y vigorosas resultaban molestas y peligrosas, porque, entre otros motivos, poseían una estructura y entramado muy valiosos susceptibles de ser aprovechados por la oposición. Además, en el seno de estas organizaciones, con sus críticas y su forma de actuar, existía la posibilidad de una opción política plural, teniendo cada militante capacidad de integrarse en cualquier grupo de la oposición. Era lo que temían la jerarquía y el gobierno y, por eso, políticos y eclesiásticos decidieron acabar con este embrión oposicional, sin importarles su avanzado estado de gestación. Justamente cuando los movimientos adoptaban una actitud critica ante los acontecimientos sociopolíticos se les exigió una renuncia a toda participación activa en la vida pública, en aras de un testimonio religioso.

En el Pais Vasco había otro factor a tener en cuenta. Todo lo anterior se mezclaba con un sentimiento nacionalista en los grupos de la AC. La concienciación obrera caló más fuerte en las zonas industriales predominantemente habitadas por las avalanchas inmigratorias. Pero, los planteamientos nacionalistas, incluso los más radicales, tuvieron mayor implantación en las áreas rurales vizcainas y guipuzcoanas. Los jóvenes de esas zonas, motivados por los religiosos de los conventos, se agruparon en la JARC para poder llevar a cabo sus primeros contactos y dar el salto a otros grupos, incluida ETA.

Las HOAC y, sobre todo, las JOC enclavadas en las zonas rurales vascas asumieron y fortalecieron esos sentimientos conjugándolos con las reivindicaciones obreras. En sus reuniones y folletos estudiaron el sindicalismo, el marxismo, el socialismo y el capitalismo, pero también la idiosincrasia de los vascos, sus aspiraciones políticas, sus ansias independentistas y las posibilidades reivindicativas en favor del pueblo vasco. Protestaron por las torturas, por la prohibición de celebración del Aberri Eguna, por la represión de las manifestaciones obreras o por el silencio de la jerarquía sometida al régimen. Además, los militantes se enfrentan al dilema de aclarar el horizonte de su actividad sociopolíti-

Actas del I Congreso de Historia de la Iglesia y el Mundo Hispánico

Hispania Sacra, 52 (2000) 
ca: o potenciar la lucha sindical o la lucha política vasca. A partir de 1968 ETA plantea otra alternativa: se presenta como el brazo armado de las luchas obreras. En su aproximación a la realidad obrera se encontrará con las asociaciones católicas y ahí intentará mostrarse como una vía de acción radical, atractiva para los militantes más jóvenes y con menos capacidad de distancia crítica. Incluso en estos años se planteó la posibilidad de crear una federación vasca de movimientos apostólicos que encuadrara Navarra, Gipuzkoa, Alava y Bizkaia.

Cuando los militantes llegaron a la madurez, encontraron dificultades en el seno de la Iglesia. Muchos de ellos fueron considerados cristianos «desviados y peligrosos». Al final, los Obispos habían domeñado a los movimientos especializados de la Acción Católica. Cuando la semilla había germinado, la trasplantaron a otros grupos para evitar problemas a la Iglesia con el gobierno. Era la jugada maestra del Vaticano que en estos años no estaba de acuerdo con el régimen, pero lo apoyaba oficialmente con un Concordato. Si hubieran continuado favoreciendo a los movimientos especializados, la jerarquía al completo se habría colocado en la oposición al régimen. Se curaron en salud antes de que los movimientos especializados confluyeran como tales con grupos políticos o fueran el fundamento de futuros partidos. Era preferible que los militantes optaran según sus preferencias, por irse a casa o por integrarse en otros grupos clandestinos, sin excluir los radicales. Hubiera sido más peligrosa la pluralidad política de unos grupos apostólicos, con unos conceptos claros de justicia y libertad. Por eso, domesticaron unos elementos molestos para la jerarquía y para el gobierno.

Las presiones políticas intentaron controlar la dinámica contestataria de las organizaciones de la iglesia, que progresivamente presentaban un frente más amplio. Las consecuencias a corto y largo plazo fueron muy diversas. Por un lado, provocaron en los propios movimientos una fuerte reacción antijerárquica y presentan como alternativa las comunidades de base. Por otra parte, la dificultad de promover la reivindicación nacionalista y la justicia social mediante unas agrupaciones católicas, obligó a sacerdotes y laicos a elegir organizaciones estrictamente políticas, abandonando, en muchas ocasiones, la Iglesia. Esto explica el importante papel que exmilitantes católicos jugarán en la transición política. Pero en el País Vasco, las incomodidades para el régimen continuaron porque las sucesivas medidas no consiguieron eliminar las opciones políticas a favor de los obreros y de los nacionalistas de muchos sacerdotes vascos.

La inestabilidad laboral aumentó progresivamente en 1967. El conflicto de Bandas fue paradigmático por su duración, pero también por la solidaridad obrera y por el comienzo de la politización de los conflictos laborales. La reacción gubernamental fue la mejor ocasión para incorporar las peticiones obreras a las de la oposición, a fin de convencer a los trabajadores de la necesidad de bregar por sus derechos sociopolíticos si aspiraban a alcanzar los laborales. 
Además del apoyo económico y moral ofrecido a los huelguistas por algunos sacerdotes, otros protagonizaron una «marcha pacifica y silenciosa» en Bilbao. Esta manifestación supone una renovación en los métodos no en el contenido de la protesta. Se inserta plenamente en la línea de denuncia inaugurada por el documento de los 339 . Es una versión muy resumida de las principales demandas de este sector del clero. Las promociones más recientes del clero habían apostado por la renovación de la protesta con procedimientos llamativos. No todos les siguieron. La adopción de medidas excepcionales retrajo a una parte del clero contestatario de la diócesis bilbaina. El empleo de medidas de fuerza supuso una de las primeras fisuras en el grupo radical.

El verano del 68 fue decisivo para la evolución sociopolítica del País Vasco. La primera ocasión de haber parado el proceso fue tras las dos muertes de junio de 1968. Las torpezas de unos y otros lo convirtieron en una oportunidad perdida. El gobernador prohibió los funerales por Etxebarrieta, mientras celebró solemnemente los sufragios por el alma del guardia. Así, convirtió la celebración y la asistencia a unas u otras misas en signo de oposición o adhesión al régimen. En apenas dos meses el Obispado bilbaino fue ocupado en dos ocasiones, junio y agosto de 1968, por un grupo de sacerdotes. Con la incorporación de actores jóvenes - tan sólo una cuarta parte había firmado el documento de los 339- y un argumento similar disputaron los primeros puestos de la cartelera junto a los incidentes sociopolíticos del conflictivo verano del 68. La denuncia de la represión sufrida por el pueblo vasco desde la guerra civil agudizada en los últimos años, la crítica al vergonzoso silencio jerárquico y la solidaridad con los sacerdotes afectados por multas y detenciones delimitaban el contenido de los dos escritos entregados al Obispo. El objetivo concreto de la permanencia en el Obispado era presionar al Prelado. Buscaban una toma de postura claramente a favor o en contra de la represión sufrida por el pueblo.

Tras el segundo encierro, el Obispo accedió a nombrar un Delegado Episcopal ad tempus para todos los asuntos sociopastorales relacionados con el clero. La consecución de estos fines mediante una medida excepcional les reafirmó su idea de que eran esos los métodos más eficaces. El empleo de estos medios produjo una fisura dentro de este grupo, al apartar a muchos curas que, aunque embarcados en las mismas reivindicaciones, no estaban dispuestos a emprender una radicalización eclesial e innegablemente política, cuyo final era difícil de prever. De este encierro surgió el lema "Gogorkeriaren aurka, gogortasuna» para definir las actuaciones posteriores de este grupo de sacerdotes que, desde entonces, será conocido como GOGOR. Al igual que en la sociedad civil un grupo había optado por la violencia, dentro del clero también un sector minoritario reconoció en la fuerza la única solución para «liberar el pueblo vasco» de la opresión que sufría incluso por parte de la Iglesia.

Actas del I Congreso de Historia de la Iglesia y el Mundo Hispánico

Hispania Sacra, 52 (2000) 
El nombramiento de un Delegado ad tempus fue uno de los pocos cambios en la actitud del Obispo en relación con sus subordinados. Pocos días antes, recordémoslo, su colega donostiarra había acusado al gobiemo de violar el Concordato. Obedecían ambos Prelados a la voluntad de cambio en la Santa Sede respecto al gobiemo español. No era fácil desandar el camino. Monsefior Gúrpide, presionado por las circunstancias y por instancias superiores, cedió parte del control a una persona con un talante diferente al suyo que, presumiblemente, iba a imprimir un carácter distinto al tratamiento de los problemas internos y externos. Sin embargo, solucionada la ocupación del obispado, sus funciones quedaron relegadas a ser meramente asesoras. La consecuencia inmediata fue la dimisión irrevocable presentada el 5 de septiembre de 1968 por el Delegado y la Comisión Asesora.

Otra vez los dirigentes diocesanos perdieron la oportunidad de asegurarse el apoyo del grupo mayoritario, brindando al grupo radical un flamante motivo de queja y un claro argumento para autoconvencerse y persuadir de la necesidad de utilizar la fuerza y medidas llamativas y cuanto más, mejor. El Encierro de Derio suponía, como en 1960 el escrito de los 339, la unión de dos generaciones sacerdotales en una nueva forma de lucha llamativa por ser más radical en sus demandas eclesiales y sociopolíticas. Utilizaron nuevamente la carta-denuncia elevada a la Santa Sede, pero decidieron secundar el envío con una medida de fuerza. Las peticiones eran similares a las del clero vasco desde la guerra civil. Una vez más se denunciaba la connivencia y el maridaje de la jerarquía con el régimen, pero se cargaban las tintas en la acusación a la Iglesia.

La mezcla de peticiones universales y particularistas daba una pretendida ambigüedad al texto, para justificar el carácter eclesial de su acción. Sin embargo, fue una de las principales causas de su relativo fracaso, puesto que las reformas eclesiásticas reivindicadas eran de tal envergadura que llevarlas a cabo hubiera supuesto un cataclismo en la Iglesia. En este punto eran conscientes de que las posibilidades de obtener una respuesta satisfactoria de Roma eran mínimas, al no haber mucha predisposición a convertir una estructura jerárquica en una democrática y "federal», con plena autonomia organizativa sin práctica vinculación con el Vaticano. Estaban pidiendo otra Iglesia y con el tiempo, muchos de ellos la abandonarán.

El significado político de la acción y su éxito en este sentido son innegables. El objetivo principal era mentalizar a una mayoría más amplia para que estuviera de acuerdo con el fondo del escrito y de la acción. Lo importante era crear un clima de opinión favorable a la necesidad de liberar al pueblo y salvarlo de la opresión en todos los frentes: político, eclesial, económico, cultural y social. La excepcional medida de fuerza suponía la presentación en sociedad de la radicalización de los procedimientos clericales como mejor forma de lucha en aras de 
una mayor eficacia para colmar las aspiraciones del pueblo vasco. Acostumbraron a la opinión pública a juzgar el contenido de las acciones, no sus procedimientos y, sobre todo, insistieron en que la Iglesia les había cerrado todas las puertas y había imposibilitado toda su acción a favor del pueblo vasco.

Mientras todos los testimonios de apoyo y en contra del encierro se sucedian por doquier, sacerdotes y jerarquía no cambiaron de actitud, por lo que se prolongó una situación con visos de difícil solución mientras la salud del obispo empeoraba día a día. Con la muerte de Monsefior Gúrpide el 18 de noviembre, acababa su conflictivo e incomprendido mandato. Ni él entendió las necesidades de su clero, ni los que le rodearon supieron aconsejarle bien a la hora de calmar los ánimos intradiocesanos. La clave (anti-gúrpide» de todas las reacciones había desaparecido, pero con ella no quedaron atrás las protestas del grupo más radical de la diócesis, que de momento continuaba protagonizando el encierro.

El día 20 de noviembre de 1867 Monseñor Cirarda, Obispo de Santander, fue nombrado Administrador Apostólico de la diócesis de Bilbao. A pesar de que con ello se atendía una de las peticiones inmediatas de los encerrados, estos no abandonaron el Seminario ni siquiera cuando el nuevo dirigente diocesano les levantó la suspensión a divinis decretada por su antecesor. Cirarda recibirá las primeras críticas, precisamente, por el levantamiento de las penas. El fin del encierro no suponía un abandono del camino iniciado con esta acción, por lo que no descartaron la posibilidad de volver a recurrir a medidas excepcionales. Desde luego no firmaban un cheque en blanco a Cirarda. Le daban un voto de confianza condicionado y aún a sabiendas de que muchas de sus peticiones no eran posibles. De momento sólo se había solucionado el problema concreto del encierro, pero muchos de los problemas continuaban aquejando a la diócesis.

\section{NUEVOS DIRIGENTES, PROBLEMAS VIEJOS}

A finales de 1968, con apenas un mes de diferencia, fallecieron los Obispos de Bilbao y San Sebastián. La situación de ambas sedes requería un nuevo estilo en el tratamiento de los problemas intradiocesanos. Para la diócesis donostiarra se eligió a un Obispo vasco que con sus primeras actuaciones supo ganarse la confianza del clero guipuzcoano. La muerte de Monseñor Gúrpide en el momento más caótico atravesado por la sede bilbaina exigía una decisión urgente. No podía correrse el riesgo de un Obispo a imagen y semejanza de Franco y la Santa Sede nombró un administrador apostólico, cuya primera tarea fue solucionar el conflicto del Encierro de Derio. Con nitidas indicaciones para un acercamiento a sus diocesanos, tanto Monseñor Argaya como Monseñor Cirarda

Actas del I Congreso de Historia de la Iglesia y el Mundo Hispánico Hispania Sacra, S2 (2000) 
imprimieron un talante muy diferente a las relaciones de sus Obispados con el poder civil.

En San Sebastián potenciaron la línea prefijada por las últimas actuaciones de Monsefior Bereciartua. En Bilbao, para deshacer los entuertos de la gestión Gúrpide, retomaron el rumbo señalado por el Delegado ad tempus en agosto de 1968. Mantuvieron un complicado equilibrio en sus relaciones con el poder civil, a la vez que afrontaron la doble oposición de los grupos minoritarios. El radical estimó insuficientes los pasos de la jerarquía y no cejó en su empeño reivindicativo en aras de una mayor libertad de la Iglesia en la que hubiera un puesto para el pueblo vasco. El grupo integrista, organizado en Hermandades sacerdotales, añoraba el catolicismo español tradicional y la colaboración con las autoridades civiles. Ambos Prelados buscaron el apoyo de los grupos mayoritarios de sus diócesis y los incluyeron en los equipos de gobierno diocesanos.

Renovados los equipos diocesanos, los Obispos se replantearon el compromiso con el poder civil dentro del nuevo contexto de relaciones Iglesia-Estado. Emprendieron un nuevo camino, pero continuaron tropezando y esquivando el obstáculo del problema vasco. Las autoridades civiles vieron en la nueva jerarquía una escasa predisposición a colaborar con ellos al negar la autorización para el procesamiento de clérigos. En 1969, las detenciones de sacerdotes y del vicario de pastoral por su presunta vinculación con activistas de ETA convulsionaron la convivencia intradiocesana y enrarecieron el ambiente sociopolítico de Bizkaia.

El grupo del Gogor, cada vez con menos efectivos, reemprendió las acciones excepcionales con una huelga de hambre en el Obispado. La celebración del Juicio de Burgos recrudeció las tensiones en la sociedad y en la Iglesia vasca, sobre todo en Bizkaia donde la prolongación de la administración apostólica llevaba consigo un estado de provisionalidad que no permitía superar los conflictos. Cirarda terminó su mandato en la más absoluta incomprensión y con la soledad del corredor de fondo. Quizá no fuera el mejor agradecimiento a un prelado, fiel seguidor de las directrices vaticanas, que, con vacilaciones, reorientó las relaciones internas y externas, allanando el camino a su sucesor. Además, no podemos dejar de señalar que Monseñor Cirarda reorganizó la Curia, constituyó el Consejo Presbiteral, renovó el Seminario, promovió una acción pastoral litúrgica y catequética en castellano y euskera, propugnó la revisión de la Acción Católica y de todo el apostolado seglar con la puesta en marcha de su naciente Consejo de Laicos y la creación de zonas pastorales. En definitiva, introdujo novedades en la organización interna de la diócesis que, en un principio, atenuaron los conflictos intradiocesanos, al rsponder a las peticiones de la mayoría manteniendo una dificil equidistancia respecto a los extremos. 
En la década de los 70, el nombramiento de Añoveros para Bilbao y de Setién como auxiliar de la diócesis donostiarra preocupó a las autoridades civiles. Con Añoveros al frente de la diócesis bilbaina y con Setién como auxiliar de la donostiarra habían perdido definitivamente en el País Vasco la posibilidad de encontrar una jerarquía dócil y plegable a los deseos gubernamentales. Monseñor Peralta, continuaba contra el viento y la marea de las protestas internas, al frente de la sede vitoriana. Aunque los informes oficiales consignaran que la figura del Prelado alavés obstaculizaba la máxima pretensión del clero radical vasco, una Conferencia Episcopal Vasca, era un escaso consuelo cuando el Vaticano había dado jaque mate al derecho de presentación de Obispos precisamente en las dos diócesis en donde, al ser más conflictivas, necesitaba más colaboración jerárquica para controlar y/o castigar a los sacerdotes díscolos.

Las esperanzas gubernamentales de cambio respecto a la actuación de Cirarda y Argaya se vieron truncadas cuando Añoveros mantuvo el mismo equipo de gobierno de sus antecesores, para no dar ningún argumento a los que habían hablado de desautorización a la gestión cirardiana. La llegada de un Obispo auxiliar a Gipuzkoa obedecía a un intento de apuntalar y profundizar la línea iniciada por Ârgaya. Así, Añoveros y Setién fueron los encargados de promover el auténtico alejamiento entre autoridades civiles y eclesiásticas en sus dos diócesis. En 1973, tras el rodaje de los años anteriores, afrontarán conjuntamente el problema de los sacerdotes presos y de la cárcel de Zamora, punto negro en la conciencia de la Iglesia española.

Con esta trayectoria el conflicto llegará, en Bilbao, a la cúpula. El afrontamiento de un asunto intradiocesano desembocará, casi sin saber cómo, en un choque concordatario más grave de lo ansiado por ambas potestades. Todo estuvo pendiente de un hilo, pero la prudencia política del achacoso Franco calmó unos ánimos en exceso exacerbados que, sin embargo, dieron al traste con la deseada, pero más supuesta que real, apertura del franquismo, con la que el presidente Arias Navarro había sorprendido a propios y extraños en el discurso del 12 de febrero.

La línea inmovilista del gobierno español salió favorecida y, en Bilbao, la oligarquía se apuntó un tanto después de manejar en la penumbra unos hilos contra un Obispo que, además de recordar los deberes sociales de los católicos empresarios hacia sus no tan cumplidores obreros, les daba lecciones de unidad en la diversidad. Por mal entendida y mal interpretada o quizá excesivamente bien comprendida la homilia-catequesis de Añoveros encendió una chispa de un polvorín que llevaba muchos años preparado.

El llamado problema vasco salió, esta vez, a la palestra de la mano de un Obispo. En principio la reacción gubernamental pudo parecer desmedida, pero conocida la trayectoria anterior no fue en absoluto sorprendente. Hasta ese 
momento todas las predicaciones testimoniales atentatorias contra la unidad nacional habían sido castigadas con duras sanciones económicas o en su defecto arrestos sustitutorios. En esa línea el Gobiemo respondió a la medida de la categoría del autor de la homilía, al ser un Obispo era más difícil la labor punitiva, pero encontró la solución en el arresto domiciliario de Monsefior Añoveros y de su Vicario de Pastoral. Pocos días después, incluso les ordenó a ambos el abandono de la diócesis, pero Monseñor Añoveros resistió diciendo que no saldría hasta recibir una orden del Papa, planteando la posibilidad de una excomunión a quien utilizara la fuerza contra un Obispo.

Si por un simple sermón dominical, las autoridades civiles imponian cuantiosas multas y arrestos sustitutorios, la respuesta gubernamental ante quién desde una pastoral había osado referirse al tema tabú de la pluralidad española no podía ser otra, por muy Obispo que fuera el responsable. Por otra parte, el gobierno, dos meses después del asesinato de Carrero, no estaba por la labor de afrontar un problema, el vasco, ante el que estaba poco dispuesto a hacer concesiones. Los partidarios del franquismo con Franco o sin Franco y los inmovilistas de toda la vida desorbitaron un problema en principio intradiocesano. La pérdida de papeles de los responsables del gobierno es la mejor confirmación de la situación a la defensiva en que se hallaba el régimen y de su falta de visión y de comprensión para el problema del País Vasco.

Mientras Bilbao, el País Vasco y el episcopado español apoyaban incondicionalmente al casi desterrado obispo, Franco tuvo que desandar el camino andado y aceptar las recomendaciones vaticanas. Fue la guinda de los conflictos Iglesia-Estado al final de franquismo, pero desde luego no fue el único problema de los últimos y agónicos affos de un régimen mantenido no artificialmente como su creador en los últimos meses de «vida», sino con una energía interna que tardaría años en extinguirse.

El caso Añoveros había acallado las demandas de gran parte del clero de las diócesis vascas, pero en 1975 volvieron a levantarse voces en contra de los desmanes del régimen de Franco, cuya respuesta ante los numerosos conflictos no fue otra que la represión a todos los eclesiásticos y seglares protagonistas y/o responsables de las tensiones. De la dureza represiva y la inflexibilidad de1 franquismo en su último año de existencia hablan por sí solos el estado de excepción y, sobre todo, las cinco ejecuciones en medio de un clamor general de protesta. Esta despedida comprometió definitivamente en el exterior la imagen del sistema político franquista. En el interior avivó la protesta clerical contra un régimen que, a pesar de todo, siempre había presumido de su catolicismo y respeto a la doctrina cristiana.

Tras la tensión vivida durante el «Caso Añoveros», las diócesis vascas, sobre todo, Bizkaia despiertan con la resaca de haber estado en candelero sin haber 
deseado estar tanto tiempo. En medio de una galbana diocesana, los acontecimientos sociopolíticos, de un año especialmente conflictivo, golpean con fuerza las conciencias de sacerdotes y Obispos del País Vasco. El Estado de excepción decretado en abril de 1975 en Bizkaia y Gipuzkoa vuelve a unir a los sacerdotes radicales de las diócesis vascas, incluida Navarra, en una denuncia colectiva. La homilía colectiva critica la conducta jerárquica de condena de la violencia "venga de donde venga» y presenta la violencia institucionalizada como causa y atenuante, a la vez, de las otras violencias. Denuncian, además, los malos tratos infligidos a los detenidos, incluidos los sacerdotes, con absoluto desprecio a la dignidad de la persona humana.

La predicación testimonial en 1975 aumentó al mismo tiempo que los acontecimientos. $\mathrm{Y}$ de forma paralela el número de multas, diligencias y arrestos sustitutorios. En su recta final, el régimen avanzaba, sin frenos, hacia una política represiva cada vez de mayor dureza. Caso omiso hicieron de las recomendaciones y reproches que muchos sacerdotes del País Vasco les hicieron desde el púlpito. Por el contrario, inmersos en un círculo vicioso de respuesta inmediata ante cualquier acto de provocación «subversiva», aumentaron, como ya hemos dicho, las homilías multadas.

Esta escalada de violencia y la dureza represiva sirvió de acicate para unir los esfuerzos eclesiales. Junto a las gestiones episcopales de Añoveros y Setién, un centenar de sacerdotes guipuzcoanos suspendieron la homilia sustituyéndola por unos minutos de silencio y continuaron reuniéndose para plantearse futuras actuaciones inmediatas. Monsefior Setién predica en Aránzazu, denunciando algunos intereses sociopolíticos que se ponen por encima de la justicia, el amor... y reivindicando el derecho del pueblo a conservar su propias peculiaridades.

El anuncio de las penas de muerte provocó una ola general de solidaridad, los Obispados de San Sebastián y Bilbao publicaron sendas notas informativas en las que advertían que «la conciencia cristiana no puede admitir un empleo legal de la fuerza que vaya más allá del necesario, porque todo exceso en la fuerza de la represión es también violenciay). Junto a las medidas intradiocesanas del País Vasco, otras instancias eclesiásticas, incluido el Papa, solicitan clemencia para los condenados a muerte. Pero ni las voces colectivas, ni las individuales, ni las jerárquicas ni las meramente sacerdotales ni la voz unánime de protesta en la calle fueron tenidas en cuenta por un gobierno obsesionado por endurecer su represión contra los terroristas, sin prever las consecuencias negativas que una medida tan impopular puede tener sobre la sociedad que por empatía se va a solidarizar indirectamente con la causa que representan los condenados.

Temeroso ante todo aquello que pudiera de forma auténtica o supuestamente amenazar la unidad nacional, el gobierno no supo ver que la violencia de la

Actas del I Congreso de Historia de la Iglesia y el Mundo Hispánico Hispania Sacra, 52 (2000) 
represión no solucionaba los problemas políticos de fondo, entre ellos el del País Vasco, que sólo podían solucionarse mediante un cambio profundo de las estructuras políticas españolas. A eso no estaba dispuesta la facción inmovilista. Mientras Franco luchaba por su vida y los avances informativos tenían en vilo a la población espanola, expectante ante la muerte del Dictador y sus posibles consecuencias, el sistema político que él había creado se debatía, afectado por una fortísima crisis económica, en una guerra intestina entre las dos tendencias inmovilista y aperturista. La represión impuesta por el Búnker eran los últimos coletazos de un régimen que, como tal, y a punto de morir su fundador, estaba herido de muerte. Fue una cruel despedida que además tiró por tierra toda la labor propagandística en el exterior. Con mayor acritud que en su momento el Juicio de Burgos, las 5 ejecuciones de septiembre de 1975 fueron, en realidad, la sentencia de muerte del propio régimen, cuya credibilidad era imposible recomponer en el exterior y mucho menos en el interior, sobre todo cuando la crisis económica amenazaba con cebarse en un país en plena agonía política.

La oleada de conflictos y ejecuciones habia permitido elevar en la Iglesia del País Vasco un clamor general de protesta y las homilías multadas estuvieron a la orden del día. Habrá que esperar a la muerte de Franco, para hallar un gesto de buena voluntad y, sólo entonces, muchas de las que estaban pendientes de pago con fecha de la muerte de Franco fueron condonadas y los que cumplían el arresto pertinente fueron puestos en libertad. Era un gesto de buena voluntad hacia una Iglesia que, con Tarancón al frente, legitimará el nuevo orden político que surge indeciso tras el franquismo. La Iglesia, una vez más había dado un espaldarazo moral a un nuevo régimen. En el País Vasco la Iglesia, convertida en beligerante contra la dictadura franquista, ha perdido efectivos (cien secularizaciones censadas) y ha quemado muchas etapas en la concienciación de muchos sectores de la población. Pero, llegada la democracia y los partidos políticos, la función parapolítica de muchos sacerdotes ya no tiene razón de ser. Había que renovar el contenido del compromiso por el que tanto se había abogado en el franquismo. La clave "antidictadura» había desaparecido y la pérdida del papel social del sacerdote en el País Vasco en este sentido fue notable y un factor más que añadir en la crisis religiosa y la división interna que recorría las tres diócesis vascas.

El descenso alarmante de efectivos clericales, provocado por las secularizaciones y por el efecto negativo de la crisis sacerdotal incapaz de generar nuevas vocaciones en una sociedad que se secularizaba a marchas forzadas, fue el primer efecto negativo de la situación atravesada por las diócesis vascas en los años 60. A largo plazo la conflictividad interna y externa dejaron exhaustas a unas comunidades diocesanas en las que muchos de sus miembros, a pesar de una encomiable labor a favor de las libertades y de los derechos humanos con- 
culcados por la dictadura franquista, habían dispersado demasiados esfuerzos en conflictos sociopolíticos. Esto, junto a las escisiones dificilmente superables de la noche a la mafiana, fueron los lastres más importantes con que la Iglesia en el País Vasco emprendió una nueva etapa en la que, decidida y decisivamente, retomó la puesta al día de sus estructuras pastorales para un mejor servicio a una sociedad muy polarizada y conflictiva.

El tardofranquismo y la transición política provocaron un vaciamiento de militantes y líderes en los movimientos laicales sumiéndolas en una crisis de la que se fueron recuperando bajo otras formas. No es posible calibrar el peso que este factor laical ha tenido en el proceso y orientación de determinadas corrientes de acción sindical y política, que abarcan todo el espectro de las fuerzas políticas vascas. Es dificil de cuantificar, porque hablar de la estructura laical del País Vasco es abarcar algo tan diverso como la sociedad misma en que está inmersa. Tras haber superado los avatares y crisis del final de franquismo, muestran un índice de actividad superior al de otras instituciones sociales y cumplen una función mediadora en al sociedad vasca no suficientemente valorada por los analistas políticos de diverso signo. Políticamente, más que los sacerdotes serán muchos de sus antiguos efectivos, como sacerdotes o ex-militantes de grupos especializados, los que desempeñarán una importante labor en la transición.

Como hemos visto, la época coincidente con el Postconcilio habia tenido en la diócesis de Bilbao en los afios 1965-1975 un carácter marcadamente conflictivo. El movimiento de reforma eclesial vivió momentos dramáticos, tanto por los conflictos cívicos como por el agrietamiento y enfrentamiento entre grupos eclesiales con diversas tendencias. Se habian venido introduciendo en la vida de la Iglesia de Bizkaia distintas reformas parciales de carácter litúrgico, catequético, de ordenación estructural y de presencia cultural y social, pero no se había organizado en la diócesis ningún proceso prolongado y ampliamente participado de reflexión cristiana sobre la propia realidad a la luz de los textos conciliares y postconciliares.

Con todo no podemos dejar de mencionar el Plan de Pastoral de 1973. Sus orígenes se remontan a la primera reunión de los vicarios de zona en enero de 1970 con el A.A. don José María Cirarda. Una vez detectada la necesidad de un plan diocesano, el Consejo Presbiteral fijó en marzo de 1970 los objetivos pastorales hasta 1973. Al poco tiempo de la llegada de Añoveros, el mismo Consejo formuló las propuestas que deberían ser recogidas en el futuro plan. Completado todo ello con apartaciones del Consejo de Laicos y de diferentes grupos, el plan fue elaborado en su fase final por el Consejo Presbiteral y los vicarios.

El plan venía exigido por una doble preocupación. Por una parte, la Iglesia local caía en la cuenta de que una confianza ingenua en el llamado cristianismo

Actas del I Congreso de Historia de la Iglesia y el Mundo Hispánico Hispania Sacra, 52 (2000) 
sociológico le había llevado a descuidar la evangelización y que, por ello se hacía preciso recordar y subrayar la dimensión misionera. Por otra parte, la recepción del Vaticano II traía consigo la pregunta por el modo más adecuado de convertirse en Iglesia servidora en un tiempo y lugar concretos. En un entrono social caracterizado por el cambio, la Iglesia local, en línea con la imagen de Iglesia del concilio se define como "comunidad misionera», que, atendiendo a las preocupaciones y problemas de los hombres y mujeres concretos, quería servir como instrumento de su liberación radical como hijos/as de Dios. Se descubría un pueblo insuficientemente evangelizado, una muy frágil unidad eclesial y social así como unas estrutcturas eclesiales necesitadas de reforma en clave evangelizadora. De ahí que los objetivos prioritarios consistieran en acentuar la evangelización, impulsar la reconciliación y tanto en la iglesia como la sociedad y promover la reforma estructural de la diócesis. El Plan, a través de objetivos parciales que anualmente se desprendían de él marcó un decenio en la vida de la iglesia local, concretamente hasta la convoncatoria de la Asamblea Diocesana, al comienzo del curso 1984-1985.

\section{LA DÉCADA DE LOS 80}

En la década de los 80, la Iglesia en general se introduce en la que ha sido descrita como segunda fase de la recepción conciliar. Las circunstancias históricas de este periodo han cambiado sustancialmente y tanto la sociedad como la iglesia vascas viven una épcoa de mayor serenidad que facilita el diálogo y permite avanzar en la recomposición de un tejido eclesial fuertemente sacudido en los años anteriores. Por otra parte, la nueva sociedad en proceso de cambio sociopolítico y de secularización cultural planteaba nuevos desafios a toda la Iglesia de Bizkaia, con importantes retos a la juventud, a la familia, a la transmisión de la fe y a las formas de presencia en los distintos ambientes diocesanos.

La idea de una Asamblea del Pueblo de Dios en Bizkaia surge en el Consejo Presbiteral, prevaleciendo sobre otra propuesta anterior de «Asamblea del Clero». Al comienzo del curso 1984-1985, los Obispos convocan oficialmente a los cristianos a participar en la Asamblea Diocesana, al mismo tiempo que constituyen una Comisión Organizadora y determinan los temas que serán tratados. La Asamblea Diocesana significa para la Iglesia de Bizkaia un amplio movimiento de reflexión para tomar conciencia de la situación propia. Viene a ser un punto de encuentro entre la recepción progresiva del Vaticano II y la situación histórica concreta En todo el proceso el laicado ocupa un lugar muy importante. La Asamblea se puede definir como un amplio proceso participativo en grupos, 
con tiempos de oración, diálogo, reflexión sobre la vida, el Evangelio y textos del Magisterio Eclesial, con el fin de decidir en niveles escalonados los compromisos personales, grupales e institucionales de carácter operativo. La llamada «lectura implicativa» de los grupos adquirió un gran relieve en la etapa final.

Tras el largo proceso de la Asamblea Diocesana (hasta el curso 1986-1987), los Obispos de Bilbao, don Luis María y su auxiliar don Juan María Uriarte, publicaron un texto muy significativo en el que, entre otras cosas, sefialaron como compromisos inmediatos la elaboración de un Plan Diocesano, la Creación del Consejo Pastoral Diocesano como órgano de máxima representatividad de toda la diócesis, y la puesta en marcha de un servicio para promover, coordinar y programar en la diócesis la formación humana, teológica, espiritual y apostólica del laicado. Efectivamente, pronto se pone en marcha el Servicio Diocesano de Formación de Laicos que clarifica los proyectos de formación integral del laicado, si bien las ofertas efectivas no llegan hasta el curso 1989-1990.

El Consejo Pastoral Diocesano fue una aspiración largamente sentida en la diócesis de Bilbao. Hubo una primera realización en la etapa final del episcopado de Gúrpide, pero faltaba el tejido representativo diocesano y la experiencia de corresponsabilidad. A partir de 1969, se abre un proceso a largo plazo creando el Consejo Presbiteral, el de Laicos y el de Religiosos. En 1988 se crea el Consejo Pastoral Diocesano como institución heredera de la Asamblea para encauzar sus conclusiones hacia la planificación diocesana. La primera encomienda episcopal fue la elaboración de un Plan Diocesano siguiendo las directrices de la Asamblea Diocesana. El Primer Plan Diocesano de Evangelización (1990-1995) tiene como principal objetivo de consolidar el tejido eclesial diocesano, estimulando su presencia adulta en la sociedad vizcaína.

El conjunto Asamblea-Plan Diocesano de Evangelización se manifiesta como un proceso unitario de reconversión de la Iglesia de Bizkaia, en un contexto histórico en el que confluyen las energías espirituales emanadas del Vaticano Il y el denso cambio social, económico, político y cultural de las últimas décadas del siglo XX. En todos estos procesos, es indudable el papel que han desempefiado y desempeñan el clero y el laicado vascos. La Iglesia vasca es un fiel reflejo del momento histórico en que vive y no cabe duda de que las cuestiones sociopolíticas influyen en la pastoral diocesana, que se ve afectada y enriquecida por el pluralismo de realidades existentes en el País Vasco. Desde 1995, Monseñor Blázquez y su auxiliar, Carmelo Etxenagusia están al frente de la diócesis de Bilbao, cuya vida transcurre con una normalidad aceptable. Acabamos de inaugurar el segundo curso del Segundo Plan Diocesano de Evangelización (1998-2003).

A golpe de acontecimientos, los asuntos de la Iglesia vasca han alcanzado periódicamente importantes cotas de actualidad, siendo, sin duda, la situación 
del País Vasco en general y de su Iglesia en particular, un asunto poco investigado, pero no por ello poco interpretado, cuando no desenfocado. Por eso, el objetivo de esta comunicación ha sido dar varias claves para conocer la historia de la diócesis de Bilbao.

\section{Cronología básica en la historia de la Diócesis de BILBAo}

1949 Creación de la diócesis de Bilbao, separada de la de Vitoria.

1950 Llegada de don Casimiro Morcillo a la diócesis, primer Obispo de Bilbao.

1956 Bilbao y Vitoria se encuadran en la provincia eclesiástica de Burgos y San Sebastián en la de Pamplona. Llegada de Monseñor Gúrpide a Bilbao.

1960 Inauguración del Seminario dé Derio.

1968 Encierros en el Obispado. Delegación ad tempus de don José Angel Ubieta. Encierro de 60 sacerdotes en el Seminario de Derio. Muerte de don Pablo Gúrpide, al que le sucede don José María Cirarda como Administrador Apostólico.

1971 Nombramiento de Monseffor Afíoveros como Obispo de Bilbao.

1973 Plan Diocesano de Pastoral.

1974 Caso Añoveros.

1978 Renuncia de don Antonio Añoveros.

1979 Administración Apostólica de don Juan María Uriarte. Nombramiento de don Luis Maria Larrea como Obispo de Bilbao, de don José María Cirarda como Obispo de Pamplona y de Monseñor Larrauri como Obispo de Vitoria. Don Juan María Uriarte continúa como Obispo Auxiliar de Bilbao.

1980 Creación del Instituto Diocesano de Teología y Pastoral.

1983 Comienza la preparación de la Asamblea Diocesana.

1984-1987 Celebración de la Asamblea Diocesana.

1988 Creación del Consejo Pastoral Diocesano.

1990 I Plan Diocesano de Evangelización hasta 1995. En 1997 se ha puesto en marcha el II Plan Diocesano de Evangelización.

1995 Llegada de Monseñor Blázquez a Bilbao y nombramiento de don Carmelo Etxenagusia como Obispo Auxiliar. 


\section{BIBLIOGRAFÍA}

AGUIRRE, R., y Mardones, J. M.: «Violencia y religión en Euskadi», en Sal Terrae, n. ${ }^{\circ}$ 68 , octubre 1980.

ALDAY, J.: La voz del clero vasco en defensa de su pueblo, Ed. Ekin, 1986, 2 vols.

BARROSO, A.: Sacerdotes bajo la atenta mirada del régimen franquista. Los conflictos sociopoliticos de la Iglesia en el País Vasco desde 1960 a 1975, IDTP, Bilbao, 1995.

ESNAOLA, S., e ITURRARÁN, E.: El clero vasco en la clandestinidad (1940-1968), 2 vols, Bilbao, 1994.

García de Cortäzar, F., y FusI, J. P.: Politica, nacionalidad e Iglesia en el País Vasco, Ed. Txertoa, 1988.

IZTUETA, P.: Sociología del fenómeno contestario del clero vasco, 1940-1975, Ed. Elkar, 1981.

MANAARICUA, A.: Las nuevas diócesis de Bilbao y San Sebastián y sus antecedentes históricos, CSIC, Salamanca, 1951.

OBISPADo DE BILbaO: Paz y reconciliación. Documentos de la Iglesia en el País Vasco (1968-1990), Bilbao, 1990.

Pagola, J. A.: Una ética para la paz. Los Obispos del País Vasco (1968-1982), San Sebastián, 1992.

Perea, J.: El modelo de Iglesia subyacente en la pastoral del clero vasco (1918-1936), IDTP, Bilbao, 1991, 4 vols.

PEREA, J.: «EI clero vasco ante la violencia de ETA», Razón y Fe, mayo 1992.

RENTERIA, J.: Pueblo vasco e Iglesia: reencuentro o ruptura definitiva. Bizkaia en la diócesis de Vitoria, Bilbao, 1982.

SÁNCHEZ ERAUSKIN, J.: Por Dios hacia el Imperio. Nacionalcatolicismo en las Vascongadas del primer franquismo (1936-1945), Ed. Kriselu, 1995.

UnZUETA, A. M.: Vaticano II e Iglesia local, Bilbao, Desclée de Brouwer, IDTP, 1994.

VחLOTA, I.: La Iglesia en la sociedad española y vasca contemporáneas, DDB, Bilbao, 1985.

VV.AA.: Iglesia local. Pueblo de Dios en la historia. IDTP (ad usum privatum).

Actas del I Congreso de Historia de la Iglesia y el Mundo Hispánico

Hispania Sacra, 52 (2000) 